\section{Compositional Nutrient Diagnosis of the Greenhouse Tomato}

\author{
L.E. Parent, A. Karam, and S.A. Visser \\ Soil Science Department, Laval University, Paul-Comtois Building, Sainte- \\ Foy, Qué. G1K 7P4, Canada
}

Additional index words. diagnosis and recommendation integrated system, foliar diagnosis, Lycopersicon esculentum, principal component analysis

\begin{abstract}
Compositional nutrient diagnosis (CND) norms were computed from a diagnosis and recommendation integrated system (DRIS) databank as means and SDS of CND multinutrient ratios and CND factors characterizing the high-yielding subpopulation of greenhouse tomato (Lycopersicon esculentum Mill.) plants during the 3- to. 8-cluster developmental stages. A CND multinutrient ratio is a row-centered logratio corrected for the bounded-sum constraint to $100 \%$ of all components, including a filling value between known components and $100 \%$. CND multinutrient ratios for $\mathrm{N}, \mathrm{P}, \mathrm{K}, \mathrm{Ca}$, and $\mathrm{Mg}$ were reduced to three dimensions by principal component analysis (PCA). Varimax-rotated factors- $\left(\mathrm{N}^{\cdot} \mathrm{KCa}^{+}\right),\left(\mathrm{Ca}^{+} \mathrm{Mg}\right)$, and $\left(\mathrm{P}^{-}\right)$-were designated as contrasts describing nutrient status and equilibria in diagnostic tissues. CND nutrient indexes for $\mathrm{N}, \mathrm{P}, \mathrm{K}, \mathrm{Ca}$, and $\mathrm{Mg}$ were highly correlated with their DRIS counterparts $(r=0.964$ to 0.987$)$, using 20 independent observations. Since CND is compatible with PCA, CND could expand DRIS to a multivariate diagnostic approach projecting structured information on nutrient data into a Euclidean space. A critical sphere specific to a developmental stage could delineate the high-yielding subpopulation for diagnostic purposes. The critical radius defined using a probabilistic approach to capture the high yielders should be validated with independent fertilizer experiments.
\end{abstract}

Plant tissues possess a multivariate character with respect to elemental composition that could be interpreted for diagnostic purposes. Holland (1966) observed that the consistency of nutrient diagnosis increases until the diagnosis involves all nutrients. He anticipated a reasoned application of principal component analysis (PCA) after linearizing the functions of original variates.

Parent and Dafir ( 1992) developed the concept of compositional nutrient diagnosis (CND) based on multinutrient ratios fully compatible with PCA. They showed that the diagnosis and recommendation integrated system (DRIS), based on dual ratios (Walworth and Sumner, 1987), produced a diagnosis similar to CND if the DRIS norms were similarly variable. CND is based on the theory of multivariate analysis of compositional data (Aitchison, 1986). CND recognizes that, given a change in certain nutrient proportions in the foliage, other proportions must be altered since plant composition is constrained to $100 \%$-the dry-matter content. Should DRIS and CND be related, a gap could be bridged between the DRIS bivariate and the CND multivariate approach.

Our objectives were to determine the relationship between DRIS and CND and to examine the applicability of CND to a multivariate diagnosis of the greenhouse tomato crop.

Received for publication 14 Dec. 1992. Accepted for publication 11 May 1993. This research was supported by the Natural Sciences and Engineering Research Council of Canada. The cost of publishing this paper was defrayed in part by the payment of page charges. Under postal regulations, this paper therefore must be hereby marked advertisement solely to indicate this fact.
DRIS. The DRIS norms (means and coefficients of variation of dual nutrient ratios characterizing the high-yielding subpopulation) used in this study were developed by Caron and Parent (1989) for three developmental stages of greenhouse tomato plants: 3 to 4 clusters, 5 to 6 clusters, and 7 to 8 clusters.

CND. CND nutrient norms (means and SDS of multinutrient ratios characterizing the highyielding subpopulation) for the same population as above (Caron and Parent, 1989) were computed from the nutrients $\mathrm{N}, \mathrm{P}, \mathrm{K}, \mathrm{Ca}$, and $\mathrm{Mg}$. A filling value, $\mathrm{R}$, was computed by the difference between $100 \%$ and the sum of nutrient proportions expressed as percentages of dry matter. Plant tissues were examined as structures of known (nutrients) and unknown (filling value) components adding up to $100 \%$ the dry-matter content. CND multinutrient ratios $\left(\mathrm{V}_{\mathrm{N}}\right.$ to $\left.\mathrm{V}_{\mathrm{Mg}}\right)$ of individual specimens in the whole population were expressed as:

$\mathrm{V}_{\mathrm{N}}=\ln (\mathrm{N} / \mathrm{G}), \ldots, \mathrm{V}_{\mathrm{Mg}}=\ln (\mathrm{Mg} / \mathrm{G})$

The geometric mean $(\mathrm{G})$ of all components was computed as:

$\mathrm{G}=(\mathrm{N} \times \mathrm{P} \times \mathrm{K} \times \mathrm{Ca} \times \mathrm{Mg} \times \mathrm{R})^{(1 / 6)}$

where $\mathrm{R}=(100 \%-\% \mathrm{~N}-\% \mathrm{P}-\% \mathrm{~K}-\% \mathrm{Ca}-$ $\% \mathrm{Mg}$ ).

The filling value $\mathrm{R}$ and the geometric mean $G$ would be altered and knowledge of nutrient balance should be improved if additional components, such as $\mathrm{S}, \mathrm{C}, \mathrm{H}, \mathrm{O}_{2}$, micronutrients, and metals (expressed on a common scale as percentages or fractions), could be determined and introduced into the analysis.

The CND nutrient indexes $I_{\mathrm{N}}$ to $\mathrm{I}_{\mathrm{Mg}}$ were computed using CND nutrient norms (*); i.e. means $\left(\mathrm{V}_{\mathrm{N}} *\right.$ to $\left.\mathrm{V}_{\mathrm{Mg}} *\right)$ and $\mathrm{SDS}\left(\mathrm{SD}_{\mathrm{N}} *\right.$ to $\left.\mathrm{SD}_{\mathrm{Mg}} *\right)$ :

$\begin{aligned} \mathrm{I}_{\mathrm{N}}= & \left(\mathrm{V}_{\mathrm{N}}-\mathrm{V}_{\mathrm{N}}{ }^{*}\right) / \mathrm{SD}_{\mathrm{N}}{ }^{*}, \ldots, \mathrm{I}_{\mathrm{Mg}}= \\ & \left(\mathrm{V}_{\mathrm{Mg}}-\mathrm{V}_{\mathrm{Mg}}{ }^{*}\right) / \mathrm{SD}_{\mathrm{Mg}}{ }^{*}\end{aligned}$

Twenty independent data from Visser et al. (1990) and Caron et al. (1991) were used to determine the correlation between DRIS and CND approaches.

$C N D$ factors. If PCA is performed on the high-yielding subpopulation only, a CND factor is a linear combination of CND nutrient indexes as defined by Eq. [4] (below), subject to Eq. [3]. However, the choice of the highyielding subpopulation maybe somewhat arbitrary and not necessarily representative of the range of nutrient interactions found in the whole population. The high-yielding subpopulation also maybe too small to conduct PCA. The jth CND factor $F_{j}$ was thus defined as a linear combination of multinutrient ratios standardized according to the means and SDS of CND multinutrient ratios characterizing the whole population $\left({ }^{\circ}\right)$, as follows:

$\begin{aligned} F_{j}= & a_{j 1}\left(V_{N}-V_{N}{ }^{\circ}\right) / S D_{N}{ }^{\circ}+\ldots+ \\ & a_{j 5}\left(V_{M g}-V_{M g}\right) / S D_{M g}^{\circ}\end{aligned}$

where $a_{i 1}$ to $a_{i 5}$ are factor score coefficients for nutrient indexes $\mathrm{N}$ to $\mathrm{Mg}$, successively. The factor score coefficients were generated by fist conducting PCA on population data. Factors showing eigenvalues $>100 / p$, where $p$ is the number of variates (Ovalles and Collins, 1988), were declared significant. Thus, only useful information was retained, since random information was discarded by eliminating nonsignificant factors (Legendre and Legendre, 1984). The varimax rotation redistributed the variance of significant factors to maximize the relationship between the interdependent variables. Factor score coefficients were obtained by multiplying the inverse of the correlation matrix by the matrix of varimax-rotated factor loadings.

Varimax-rotated factor loadings showing values larger than the selection criterion (SC) (Ovalles and Collins, 1988) were selected for designating factors as contrasts $(+$ or -$)$ between dominant multinutrient ratios. Nutrient interactions, dilution, or accumulation were interpreted using those selected multinutrient ratios. The SC was computed as follows:

$\mathrm{SC}=0.5 /\left(\mathrm{F}_{\mathrm{j}} \text { eigenvalue }\right)^{0.5}$

CND factor norms were computed as means and SDS of factor scores characterizing the high-yielding subpopulation (mean $\mathrm{F}^{*}$ and $\left.\mathrm{SD}_{\mathrm{Fi}}{ }^{*}\right)$. The jth CND factor index $\mathrm{I}_{\mathrm{Fj}}$ was calculated as follows:

$I_{\mathrm{Fj}}=\left(\mathrm{F}_{\mathrm{j}}-\mathrm{F}_{\mathrm{j}}{ }^{*}\right) / \mathrm{SD}_{\mathrm{Fj}}{ }^{*}$

Factor indexes (the $\mathrm{I}_{\mathrm{FI}} \mathrm{s}$ ) are factor score coordinates translated toward the origin (means) for high yielders and scaled according to the SDS for high yielders in a j-dimensional space. Standardized (SD) scaling in j orthogonal dimensions produces circular, spheroidal, 
Table 1. Compositional nutrient diagnosis (CND) multinutrient ratios $\left(V_{N}\right.$ to $\left.V_{R}\right)$ and factor norms for the high-yielding subpopulation by developmental stage for greenhouse tomatoes, and population statistics over all stages required to compute CND factors (data from Caron and Parent, 1989).

\begin{tabular}{|c|c|c|c|c|c|c|c|c|}
\hline \multirow{4}{*}{$\begin{array}{l}\text { CND } \\
\text { parameter }\end{array}$} & \multicolumn{6}{|c|}{ CND norms by developmental stage } & \multirow{3}{*}{\multicolumn{2}{|c|}{$\begin{array}{c}\text { Population } \\
\text { statistics }\end{array}$}} \\
\hline & \multicolumn{6}{|c|}{ Clusters (no.) } & & \\
\hline & \multicolumn{2}{|c|}{$3-4$} & \multicolumn{2}{|c|}{$5-6$} & \multicolumn{2}{|c|}{$7-8$} & & \\
\hline & Mean & SD & Mean & SD & Mean & SD & Mean & SD \\
\hline \multicolumn{9}{|c|}{ Row-centered logratio } \\
\hline$V_{N}^{2}$ & 0.354 & 0.071 & 0.505 & 0.093 & 0.376 & 0.066 & 0.396 & 0.147 \\
\hline$V_{p}$ & -1.392 & 0.158 & -1.361 & 0.211 & -1.441 & 0.181 & -1.447 & 0.223 \\
\hline $\mathrm{V}_{\mathrm{K}}$ & 0.380 & 0.132 & 0.311 & 0.085 & 0.486 & 0.107 & 0.286 & 0.171 \\
\hline $\mathrm{V}_{\mathrm{Ca}_{\mathrm{a}}}$ & -0.556 & 0.122 & -0.639 & 0.140 & -0.530 & 0.163 & -0.475 & 0.306 \\
\hline$V^{c a}$ & -2.085 & 0.152 & -2.209 & 0.091 & -2.289 & 0.162 & -2.188 & 0.213 \\
\hline $\ln (G)^{y / 8}$ & 1.171 & 0.114 & 1.087 & 0.123 & 1.080 & 0.087 & 1.057 & 0.136 \\
\hline \multicolumn{9}{|l|}{ CND factor } \\
\hline$\left(\mathrm{N}^{-} \mathrm{K}-\mathrm{Ca}^{+}\right)^{\mathrm{x}}$ & -0.149 & 0.450 & -0.603 & 0.421 & -0.597 & 0.343 & 0 & 1 \\
\hline$\left(\mathrm{Ca}^{+} \mathrm{Mg}\right)$ & -0.453 & 0.659 & 0.033 & 0.383 & 0.404 & 0.766 & 0 & 1 \\
\hline$\left(\mathrm{P}^{-}\right)$ & -0.198 & 0.756 & -0.458 & 0.924 & -0.024 & 0.793 & $\mathbf{0}$ & 1 \\
\hline
\end{tabular}

${ }^{2} \mathrm{G}=$ geometric mean; term used to reconstitute percentage values using Eq. [1] in text.

or hyperspheroidal (>3 dimensions) bodies in a Euclidean space.

Statistical analyses. Statistical analyses were conducted using SYSTAT 5.0 (SYSTAT, 1989) and EXCEL 2.2 (Microsoft Corp., 1989).

CND nutrient and factor norms are presented in Table 1. Using $t$ tests to compare means in each row, we found that, like DRIS (Caron and Parent, 1989), CND nutrient norms differed significantly from one developmental stage to another (data not shown). Hence, one set of norms for all developmental stages would not be as appropriate for diagnostic purposes as a set of stage-specific nutrient norms.

CND nutrient indexes Eq. [3] were highly correlated $(P \leq 0.01)$ to the corresponding DRIS indexes for N, P, K, Ca, and $\mathrm{Mg}(r=$ 0.964 to 0.987 ). The DRIS dry-matter index and the CND index $V_{R}$ showed a simple correlation coefficient of 0.949 . Indeed, dry matter, the sum of all components, differed from R, the filling value between dry-matter and nutrient components. The $\mathrm{R}$ value is the undistorted component that must be used in compositional data analysis (Aitchison, 1986). The close correlation between DRIS and CND nutrient indexes indicated that the bivariate DRIS approach can be expanded directly to a multivariate approach using CND.

Three principal components (Table 2) showed eigenvalues, each accounting for $>20 \%$ of the variation and totaling $83 \%$. The first factor, which was negatively related to $V_{N}$ and $\mathrm{V}_{\mathrm{K}}$ and positively related to $\mathrm{V}_{\mathrm{Ca}}$, was designated as $\left(\mathrm{N}^{-} \mathrm{KCa}^{+}\right) . \mathrm{V}_{\mathrm{Ca}}$ and $\mathrm{V}_{\mathrm{Mg}}$ were con- trasted in the second factor, which was designated as $\left(\mathrm{Ca}^{+} \mathrm{Mg}\right)$. The third factor was negatively related to $\mathrm{V}_{\mathrm{P}}$ and designated as $\left(\mathrm{P}^{-}\right)$. The nutrient structure of factors $\left(\mathrm{NKCa}^{+}\right)$and $\left(\mathrm{Ca}^{+} \mathrm{Mg}\right)$ built by PCA is supported by some general principles governing nutrient equilibria in tomato plants, since $\mathrm{NH}_{4}^{+}, \mathrm{K}+$, and $\mathrm{Mg}^{2+}$ ions can be antagonistic to $\mathrm{Ca}^{2+}$ (Marschner, 1986; Pill et al., 1978; Torres de Claasen and Wilcox, 1974). Factor $\left(\mathrm{NKCa}^{+}\right)$also is indicative of foliar $\mathrm{N}$ and $\mathrm{K}$ discharge and dilution vs. Ca accumulation, as related to fruit setting and plant age.

Since CND factors are orthogonal to one another, a three-dimensional Euclidean space should characterize the nutrient status in the foliage of tomato plants. A critical spheroidal body in factor index coordinates on each axis could be designed to include $95 \%$ of the highyielding subpopulation of tomato plants. The multinormal distribution is a joint distribution (Legendre and Legendre, 1984). As a result, each symmetric and standardized CND axis includes $98.3 \%$ of the high yielders (the cubic root of $95 \%$ or 0.95 is 0.983 ). The corresponding two-tail $t$ value $(P \leq 0.017)$ for each of the three standardized $\mathrm{I}_{\mathrm{Fj}} \mathrm{s}$ was $\approx 2.4$ in statistical tables. The critical radius designed here to scan the spheroidal space is a Euclidean distance, $d$ (the hypotenuse), calculated by extending the Pythagorean theorem to three dimensions: $\mathbf{d}=\left[\Sigma \mathbf{I}_{\mathrm{Fj}}^{2}\right]^{(0.5)}, \mathrm{j}=1$ to 3 . Fertilizer experiments with varying levels of major nutrients are needed to validate the critical radius defined probabilistically.

Table 2. Results of principal component analysis on compositional nutrient diagnosis (CND) multinutrient ratios found for upper mature leaves of greenhouse tomato plants during the 3- to 8-cluster developmental stages (data from Caron and Parent, 1989).

\begin{tabular}{|c|c|c|c|c|c|c|}
\hline \multirow{2}{*}{$\begin{array}{l}\overline{C N D} \\
\text { parameter }\end{array}$} & \multicolumn{3}{|c|}{ Factor loading ${ }^{z}$} & \multicolumn{3}{|c|}{ Factor score coefficient ${ }^{y}$} \\
\hline & $\mathrm{N}^{-} \mathrm{K}^{-} \mathrm{Ca}^{+}$ & $\mathrm{Ca}^{+} \mathrm{Mg}^{-}$ & $\mathrm{P}^{-}$ & $\mathrm{N}^{-} \mathbf{K}^{-} \mathrm{Ca}^{+}$ & $\mathrm{Ca}^{+} \mathrm{Mg}^{-}$ & $\mathrm{P}$ \\
\hline \multicolumn{7}{|c|}{ Row-centered logratio } \\
\hline$V_{N}^{y}$ & $-0.744^{*}$ & 0.135 & 0.128 & -0.432 & 0.146 & 0.074 \\
\hline$V_{p}$ & 0.172 & 0.100 & $-0.973^{*}$ & 0.049 & 0.083 & -0.836 \\
\hline$V_{K}$ & $-0.771^{*}$ & 0.071 & 0.174 & -0.443 & 0.096 & 0.114 \\
\hline $\mathrm{V}_{\mathrm{ca}}$ & $0.739^{\circ}$ & $0.523^{*}$ & 0.387 & 0.419 & 0.376 & 0.364 \\
\hline $\mathrm{V}_{\mathrm{Mg}}$ & 0.138 & $-0.973^{*}$ & 0.127 & 0.138 & -0.790 & 0.128 \\
\hline Eigenvalue $^{x}$ & 1.743 & 1.253 & 1.158 & & & \\
\hline
\end{tabular}

\section{${ }^{\mathrm{x}}$ For significant $(*)$ factors only.}

'For standardized row-centered logratios.

${ }^{\times}$Sum of the squares of factor loadings (total variance is 5).

Using CND factors corrects some distortion in linear modeling inherent to the DRIS approach, because it considers row-centered logratios of multinutrient expressions and the filling value $\mathrm{R}$ instead of the dry-matter content in the computation procedure. Using PCA, CND discards random information and retains only significant factors. Each varimax-rotated factor contains interpretable information on nutrient interactions, discharge, dilution, or accumulation and can be diagnosed independently with respect to a multivariate critical sphere.

\section{Literature Cited}

Aitchkon, J. 1986. Statistical analysis of compositional data. Chapman and Hall, New York.

Caron, J. and L.E. Parent. 1989. Derivation and assessment of DRIS norms for greenhouse tomatoes. Can. J. Plant Sci. 69:1027-1035.

Caron, J., L.E. Parent, and A. Gosselin. 1991. Effect of nitrogen and salinity levels in the nutrient solution on the DRIS diagnosis of greenhouse tomato. Commun. Soil Sci. Plant Anal. 22:879-892.

Holland, D.A. 1966. The interpretation of leaf analysis. J. Hort. Sci. 41:311-329.

Legendre, L. and P. Legendre. 1984. Ecologie numérique I. Le traitement multiple des données écologiques. 2nd ed. Presses l'Univ. du Québec, Canada.

Marschner, H. 1986. Mineral nutrition of higher plants. Academic, London.

Microsoft Corporation. 1989. Microsoft Excel 2.2. Microsoft Corp., Evanston, Ill.

Ovalles, F.A. and M.E. Collins. 1988. Variability of northwest Florida soils by principal component analysis. Soil Sci. Soc. Amer. J. 52:1430-1435.

Parent, L.E. and M. Dafir. 1992. A theoretical concept of compositional nutrient diagnosis. J. Amer. Soc. Hort. Sci. 117:239-242.

Pill, W.G., P. Lambeth, and T.M. Hinckley. 1978. Effects of nitrogen form and level of ion concentrations, water stress, and blossom-end rot incidence in tomato. J. Amer. Soc. Hort. Sci. 103:265-268.

SYSTAT. 1989. SYSTAT Macintosh. version 5.0. SYSTAT, Evanston Ill

Torres de Claasen, M.H. and G.E. Wilcox. 1974. Effect of nitrogen form on growth and composition of tomato and pea tissue. J. Amer. Soc. Hort. Sci. 99:171-174.

Visser, S.A., M. Caillier, A. Karam, and L.E. Parent. 1990. Biodegradation et valorisation agricole des résidus de l'industrie de la pêche. Natural Sci. Eng. Res. Council Canada, Ottawa. Rpt. STR-16294.

Walworth, J.L. and M.E. Sumner. 1987. The diagnosis and recommendation integrated system (DRIS). Adv. Soil Sci. 6:149-188.

HortScience, Vol. 28(10), OCTOBER 1993 